\title{
Physician Quality and Health Care for the Poor and Uninsured
}

Lara Bryant and Sharmila Vishwasrao

Objective. To test whether uninsured patients and patients on Medicaid are more likely to be treated by lower quality physicians within a hospital.

Data Sources. Inpatient records and hospital variables from the Florida Agency for Health Care Administration 2004-2005, physician data from the Medical Quality Assurance in the Florida Department of Health, and medical school quality from the Princeton Review’s Gourman Report. Study Design. Data on cardiac inpatient admissions were used to test for variations in physician quality between privately insured, Medicare, Medicaid and uninsured patients. Physician quality was measured using three indicators - the ranking of the medical school where the physician was trained, years of experience and board certification. Since better physicians may chose to work at hospitals with fewer uninsured patients, hospital fixed effect models were used to hold the quality level within a hospital constant. Next the data was separated by hospital ownership status to determine whether patient sorting by physician quality and patient payment type varied by hospital ownership status.

Data Collection/Abstraction Methods. Only cardiac inpatients in general or teaching hospitals that had at least 5 patients and 3 physicians. Patients must be prioritized as emergency or urgent. Principal Findings. Uninsured patients and Medicaid patients are significantly more likely to be treated by physicians from lower ranked schools, less experienced physicians and physicians who are not board certified.

Conclusion. Uninsured and Medicaid patients face barriers to care that go beyond the usual problems of access to treatment. Even when uninsured and poor patients receive treatment at hospitals, the quality of care they receive is likely to be of lower quality. 


\section{INTRODUCTION}

Health care access for the poor and uninsured in the U.S. is an increasingly complex problem. From 2000 to 2005 the number of uninsured persons in the US rose from 39.6 to 46.6 million while hundreds of hospital emergency rooms, the primary source of healthcare for many of the uninsured, were closed. Since uninsured patients are less likely to pay for care, increased demand for emergency room services by the uninsured and lower hospital payments from private insurance companies, Medicare, and Medicaid, are increasingly placing financial burdens on hospitals. Thus the poor face a health care system which while superficially guaranteeing access, has strong incentives to limit the quantity and quality of care.

A large body of empirical evidence documents adverse health outcomes for the uninsured. Baker et al. (2001) and Lichtenberg (2001) find that adult mortality and morbidity were higher for the uninsured relative to the insured. The common explanations that are advanced to explain these adverse outcomes rely on the fact that the uninsured generally use fewer preventive and screening services and are generally sicker when diagnosed. Kozak, Hall, and Owings (2001) and Pappas et al. (1997) show that the uninsured have higher rates of avoidable hospitalizations. According to the Kaiser 2003 Health Insurance Survey, three times as many uninsured patients postponed seeking care and did not fill prescriptions because of costs compared to the insured.

Adverse health outcomes for the poor and uninsured can also occur because the quality of acute and therapeutic care received by the uninsured may be worse than that received by insured patients. To determine whether the uninsured are treated differently by health providers than the insured, the majority of research has compared outcomes such as mortality rates or complication rates, or 'treatments' such as total charges, length of stay, or receipt of a specific procedure across insured and uninsured patients (Hadley 1988; Canto et al. 2000; Currie and Gruber 1996). 
Our study focuses on a previously unexplored aspect of care - the quality of physicians treating the uninsured. We study how physician quality as measured by quality of schooling, years of experience, and board certification varies based on the patient's ability to pay. In particular we are interested in whether poor or uninsured patients are treated by lower quality physicians.

The actual or perceived quality of the physician treating a patient may be correlated with patient outcomes for a number of reasons. Most obviously physicians with higher quality training are expected to provide better care. In a study of coronary artery bypass surgery in New York, Jha and Epstein (2006) show that treatment by the 'best' physicians and hospitals can reduce mortality in two common cardiac procedures by as much as $50 \%$, where quality is measured by risk-adjusted mortality rates and volume (number of cases). In addition to providing better therapeutic care, within a hospital more skilled physicians may have priority access to test results, operating rooms, and better nurses. There could be placebo effects if patients are reassured that they are under the care of the 'best' physician. There is certainly a presumption that the quality of physicians is important to patients even if the effects on the outcome are not measured. Hospitals and physician groups often advertise where their new hires were trained, and many states and insurance companies attempt to provide information about physician attributes to prospective patients.

The sorting of underinsured patients to lower quality physicians may occur at the physician level or at the hospital level. The reasons for physicians to discriminate against uninsured patients are widely known. Physicians receive payments from Medicare, Medicaid, and privately insured companies, yet payment from uninsured patients is not guaranteed. Higher quality physicians are more likely to have choices regarding how many and which patients to treat, while newer, lesser known physicians are likely to treat all patients, at least in the early 
stages of their careers. Also, since insured patients pay far less than $100 \%$ of costs, their demand for medical care is more inelastic than uninsured patients' demand for care. Thus physicians may induce more care from insured patients.

While hospitals are required to treat all patients that seek emergency care, anecdotal evidence suggests that hospitals are well informed about the exact nature of a patient's insurance coverage; any visit to a hospital typically begins with an inquiry about insurance coverage. If a hospital has financial incentives to attract insured patients over poor and uninsured patients, the hospital may sort patients not only by diagnoses but also by insurance status when assigning physicians to treat patients. Although patients cannot typically observe the quality of physician they receive upon entering a hospital, the hospital staff and administration are well informed of the physicians' quality. Thus hospitals may be able to establish formal and/or informal policies regarding treatment of the poor. For instance, in a survey of more than 2,000 physicians at U.S. health centers, 13 percent of responding faculty reported formal practice policies limiting care to uninsured patients (Weissman, Campbell, and Gokhale 2003).

Two problems need to be addressed in order to test whether there is sorting of physician quality by patients' ability to pay. The first problem is that unobserved heterogeneity in illness and other patient health characteristics can drive the physician allocation decision. If uninsured patients are healthier we might expect them to be treated by lower quality physicians. We use a number of patient characteristics such as diagnosis severity, prior cardiac conditions, an injury severity score, and dummies for eleven other common secondary diagnoses to account for such heterogeneity.

The second problem is that the quality of the physician treating a patient depends on the overall quality of physicians at the attending hospital. If overall quality of physicians is lower at 
hospitals which treat more uninsured patients, we may see a negative association between physician quality and the treatment of uninsured patients; again this would not constitute evidence of discrimination within a hospital. We examine the determinants of the quality of physician treating a patient, after controlling for the quality and frequency with which a doctor treats patients in a particular hospital relative to other physicians within the hospital. Using a hospital fixed-effect approach, we exploit within-hospital variation in treatment and explicitly control for hospital characteristics that do not vary across patients.

A number of studies have shown that hospital ownership can affect the care provided to uninsured patients (Norton and Staiger 1994; Sloan et al. 2001). We analyze this effect by separating the data by type of hospital ownership. A for-profit hospital may have stronger incentives to maximize cash flows from insured patients than would a non-profit or government hospital. For instance, for-profits have been found to bill more or 'up code' patient diagnoses (Sloan et al. 2001; Silverman and Skinner 2004). Sloan et al. (2001) also found that for-profit hospitals were more expensive to Medicare than not-for-profit hospitals, although there were no differences in health outcomes by hospital ownership.

Our findings support our hypotheses of physician sorting by insurance type for all measures of physician quality. In particular, uninsured and Medicaid patients are treated by physicians from lower ranked schools, by less experienced physicians, and are less likely to be treated by board certified physicians.

The paper is organized as follows. The next section discusses prior theoretical work on treatment quality and describes a conceptual framework within which to view the sorting of physician quality by patient's ability to pay. The Data and Methods section contains a description of the data, discusses descriptive statistics, and describes the empirical model. 
Following that, we present and discuss our empirical results. The final section concludes and identifies possible directions for future research.

\section{CONCEPTUAL FRAMEWORK}

The disconnect between payers and insured patients in health care markets results in an inherent tension between maintaining quality and minimizing costs. When health care providers are reimbursed for the cost of actual care, quality provision is high but there are few incentives to minimize costs. When reimbursed by fixed payments per treatment, providers will minimize costs but have no incentive to maintain quality. The existing literature on treatment quality has focused on the cost and quality incentives under various payment schemes under two different assumptions of patient demand. When patient demand is a function of quality, patients can enforce the maintenance of quality through their choice of health care providers (Ellis and McGuire 1986; Pope 1989). However, when the patient is not fully informed about the quality of care or when quality is an experience good, the patient's role in maintaining quality is not as effective. Ma (1994) shows that a mixture of cost reimbursement and prospective payment can be used to maintain quality and contain costs. Chalkley and Malcolmson (1998) model the behavior of providers when patient demand is independent of quality and show that either cost reductions or quality improvements are feasible, but not both, and that behavior depends on the benevolence of the providers.

When patients do not pay for health care at all (as when they are poor) a simple matching model is sufficient to show that providing high quality care to non paying patients is difficult to achieve. Consider a very simple stylized model of the health care market where patient demand is independent of quality. There are two types of physicians, low quality, indexed by L and high 
quality indexed by $\mathrm{H}$. In common with the literature on quality we assume that the costs are strictly increasing in quality so that the cost of providing care, $c_{i}, \mathrm{i}=\mathrm{H}, \mathrm{L}$ is such that $c_{H}>c_{L}$. Each patient buys one unit of health care from a physician. If the patient is insured the insurance company will pay $P_{H}$ on her behalf to the physician. An uninsured patient pays $P_{L}=0$. Assume that the price paid by the insurance company is set to insure participation by high quality physicians in the plan so that $P_{H}=c_{H}$. This ensures that both high and low quality physicians remain in the market. In this simple matching model, there are four possible matches of physicians and patients. The payoffs from all four possibilities can be ordered as follows: $P_{H}-c_{L}>P_{H}-c_{H}>P_{L}-c_{L}>P_{L}-c_{H}$. Given our assumptions on the costs of quality and payments, a hospital makes the most money when a low quality physician treats an insured patient and loses the most money when a high quality physician treats an uninsured patient.

Clearly hospitals have an incentive to reduce quality in order to increase profits in this type of model with fixed payments when quality is not contractible. Given the overall quality within a hospital, hospitals still have an incentive to discriminate in the provision of quality between insured and uninsured patients. Insured patients may find it possible to avoid the problem of the best payers being treated by the worst physicians by choosing a provider, through payment plans which monitor and enforce a certain quality level or through cost reimbursement plans. Uninsured patients do not have the same protections. Thus we would expect the average physician quality to be lower for uninsured patients within a hospital relative to insured patients.

\section{DATA AND METHODS \\ Data Description}

Our study examines all inpatients treated in Florida hospitals for procedures classified under 
the major diagnostic category (MDC) of 'Diseases and Disorders of the Circulatory System,' which are procedures related to the heart. Patient and hospital data are from the Florida Agency for Health Care Administration. We use the most recent year of patient data available - the third and fourth quarters of 2004 and first and second quarters of 2005. Florida inpatient hospital records are matched to data on physician and hospital characteristics.

Many previous studies have focused on patients with heart disease to study questions of hospital behavior towards the treatment of patients based on insurance status (Canto et al. 2000; Hadley, Steinberg, and Klag 1992; Young and Cohen 1991; Kreindel, Rosetti, and Goldberg 1997). By focusing on one medical specialty, we avoid potential estimation bias that could result from correlations between the number of uninsured within a specialty and average physician quality across specialties.

Quality of care is measured by the quality of the operating physician who treats the patient, or if the patient does not have an operating physician, the quality of the attending physician. Data on physicians are provided by the Medical Quality Assurance division of the Florida Department of Health. We use providers' first year in practice, board certification, and medical school attended to construct our measures of physician quality -years of experience, board certification in an area related to cardiac care, and school quality. Our measure of medical school quality is the score assigned by the Princeton Review's Gourman report, which scores and ranks medical schools in the U.S. and many international medical schools. Medical schools with the highest Gourman scores are expected to produce the highest quality physicians.

Board certification has requirements beyond obtaining a M.D. or D.O. and completing a residency program at an accredited school. Physicians must also pass examinations given by a specialty board, and many boards require evaluations from the physicians’ medical colleagues. 
We assume that years of experience are positively related to physician quality. For cardiacrelated procedures, several studies have shown that higher volumes of coronary artery bypass graft surgeries by hospitals and physicians are associated with lower mortality rates (Wen et al. 2006; Agency for Healthcare Research and Quality 2004). However, the exact relationship between years of experience and quality of care for all heart conditions is unclear. Although physicians with more experience may have more learning-by-doing, younger and less experienced physicians may be more familiar with the latest technologies in cardiac care.

Years of experience and patient severity are compared in Table 1, along with school quality and board certification. The negative and significant correlation between physicians' years of experience and diagnosis-related groupings (DRG codes) suggests that physicians with greater experience are treating patients who have the most difficult procedures, since lower DRG codes indicate the most difficult procedures. For example, DRG code 103 indicates a heart transplant and DRG code 143 indicates chest pain. Physicians’ years of experience is also significantly negatively correlated with patients' survival probability at diagnosis. Thus both measures of patient severity indicate that physicians with more years of experience are typically assigned to the most severely ill patients.

\section{Descriptive Statistics}

Summary statistics on patient characteristics are shown in Table 2. The patient records indicate the primary source of expected reimbursement to the hospital for service. We group the payment categories into five payment types: uninsured, Medicare, Medicaid, private insurance, and 'other' insurance. We exclude persons on 'other' insurance because they represent less than two percent of the sample, and a mix of state-county specific government policies whose 
relationship with hospital treatment is unclear.

There are 305,508 inpatient records with heart-related diagnoses that match data on hospitals and physicians. We only include patients in general or teaching hospitals and who the hospital has prioritized as an emergency or urgent admission, as opposed to an elective admission, since patients who have time to schedule appointments with physicians may be able to wait for treatment by their personal physician or obtain recommendations for a particular physician. After merging all patient, physician, and hospital data meeting these categories we have 259,054 inpatient records in our sample. Our final exclusion is to include records only if the data indicate the hospital treated at least 5 patients, and there are at least three physicians working in the hospital. After these final exclusions we have 259,046 observations for our estimated model.

\section{Methodology}

As mentioned before, a negative relationship between physician quality and uninsured patients could occur because of screening within a hospital or because of the hospital and location choices of patients. Since we are interested in testing whether screening occurs at the hospital level, we use hospital fixed effects to exploit within-hospital variation in the quality of physicians treating patients. Although much research has looked at the determinants of a patient's choice of hospital, there has been very little work on the variance in patients' treatment within a hospital. ${ }^{1}$ By using fixed effects, hospital characteristics that are constant across patients, such as administrative policies and available technology, are held constant.

To estimate a patient's treatment within a hospital, our level of observation is patientphysician-hospital specific. For the continuous measures of quality, experience and medical school score, we first obtain the median value at hospital $h$, median_qual ${ }_{h}$, across all patients 
treated in hospital $h$. By calculating the median across all patients, we account for the fact that physicians treat different numbers of patients within the hospital. The dependent variable used in the estimated model is constructed as the difference between the observed and median value of quality for physician $i$ treating patient $p:$ rel $_{-} q u a l_{\text {pih }}=o b s_{-} q u a l_{\text {pih }}-$ median $_{-} q u a l_{h}$, where $o b s_{-} q u a l_{\text {pih }}$ is the observed quality of physician $i$ treating patient $p$ in hospital $h$. We then estimate these continuous measures of physician quality as an OLS regression,

$$
\begin{array}{r}
\text { rel__ual }_{\text {pih }}=\beta_{0}+\beta_{1} \text { Uninsured }+\beta_{2} \text { Medicaid }+\beta_{3} \text { Commerical } \\
+\beta_{4} \text { Patient Characteristics }+\mu_{h}+\varepsilon_{i h}
\end{array}
$$

where $\beta_{1}, \beta_{2}, \beta_{3}$ measure the relationships between the patient payment type of uninsured, Medicaid, or commercially insured, respectively, on relative physician quality. The omitted patients are Medicare patients. Patients' health characteristics are described below; other characteristics include age indicators, indicators for patient gender and race, and indicators for day admitted (Sunday-Thursday). Finally, $\mu_{h}$ represents the hospital fixed effects.

When physician quality is measured by the quality of medical schools, we are faced with the problem that the Gourman score is unavailable for most international medical graduates (IMGs). As the score was only determined for the top international medical schools, in our sample the score is unavailable for $93 \%$ of the patients treated by IMGs. We address this issue with a selection model and proceed as if the Gourman scores are only observed for physician graduates of U.S. medical schools. We use the Heckman two step method to estimate a probit model where the dependent variable is an indicator for whether the patient was treated by a physician who graduated from a U.S. medical school. From the probit model we obtain the linear predictors in order to calculate the Mill's ratio, $\lambda$. The inverse Mill's ratio is then incorporated into equation (1) where the dependent variable is the relative Gourman score of the physician 
treating the patient. This relative score is again the medical school quality of the domesticallytrained physician treating patient $p$ in hospital $h$, relative to the median school quality across all patients treated by domestically-trained physicians within the hospital. We then estimate equation (1) only on patients who were treated by physician graduates of U.S. medical schools.

When our measure of quality is whether a physician is board certified, we estimate a probit model where the dependent variable is whether or not a patient is treated by a physician who is board certified in an area related to cardiac care:

$$
\begin{aligned}
\text { brd }_{\text {pih }}=\gamma_{0}+\gamma_{1} \text { Uninsured } & +\gamma_{2} \text { Medicaid }+\gamma_{3} \text { Commercial } \\
& +\gamma_{4} \text { Patient Characteristics }+\phi_{h}+v_{i h}
\end{aligned}
$$

where $b r d_{\text {pih }}$ is an indicator for whether or not the physician treating the patient is board certified. Letting $Q$ represent all right-hand side variables and using the usual exogeneity assumptions: $E\left(\varepsilon_{i h} \mid Q\right)=E\left(v_{i h} \mid Q\right)=0$.

As frequently discussed in the literature, there is a strong likelihood that the researcher does not observe all indicators of patient health that are perceived by hospital staff and used in treatment decisions. If there are unobserved health differences between the uninsured and insured patients’ health that influence treatment decisions, estimated results could be biased.

We include three controls for patients' health. First, within the primary cardiac diagnosis code, we categorize diagnosis related groupings (DRGs) according to average charges per case. We create four diagnoses indicators: 'very severe', 'severe', 'somewhat severe' and 'mild' where the latter is the omitted category. We expect patients with 'very severe' and 'severe' diagnoses to be treated with higher quality physicians, all else equal.

Second, we control for 11 secondary diagnoses which would indicate the health status of the patient at the time of admission, following Baker et al. (2001): diabetes, hypertension, cancer, 
dementia, stroke, vascular disease, an old myocardial infarction, other heart disease, pulmonary disease, respiratory disease, and obesity. We also include several demographic variables considered to be correlated with health: patient's age and gender, and indicators for race (African-American) and ethnicity (Hispanic).

Lastly we construct a measure of survival risk, the ICD-9 Injury Severity Score (ICISS). For each of the patient's ICD-9 diagnoses (one primary and up to nine secondary), survival risk ratios (SRRs) are derived by dividing the number of survivors in each ICD-9 code by the total number of patients with the same ICD-9 code. ICISS is calculated as the simple product of the SRRs for each of the patient's diagnoses. The ICISS has been shown to outperform other standard measures of patient severity in recent empirical work by Osler et al. (1996); Rutledge et al. (1998); and Huynh, Guy, and Rutledge (1998). We use the entire population of 2,512,406 patients to construct the ICISS.

\section{Hospital Ownership Status}

Since we are including hospital fixed effects in our estimation, we cannot obtain the effects of any hospital characteristics on this sorting process. The ownership and teaching status of hospitals are the hospital characteristics most commonly discussed in both theoretical and empirical literature. Hospitals have either government, non-profit, or private investor ownership (for-profit). In our sample we also observe whether or not a hospital is a teaching hospital. Hospitals with different ownership status have different incentives for treating poor patients, as discussed earlier. Since government hospitals are typically mandated to provide care to the poor, a greater percentage of their patients may be poor, limiting the hospitals' capacity to sort patients by insurance status to different quality physicians. 
In order to determine whether there are differences in patient sorting by physician quality across hospital ownership types, we split our sample and run equations (1) and (2) on all patients in each of the four types of hospitals: government, not-for-profit, teaching, and for-profit hospitals. Teaching hospitals are not included in the other three ownership categories because amongst both providers and patients, there is a perception that teaching hospitals a) have the highest quality physicians; and b) have a greater percentage of uninsured patients than (nonteaching) not-for-profit and for-profit hospitals. In our sample the range of physician quality was much smaller in teaching hospitals than in non-teaching hospitals, and the average quality much higher when measured by school ranking. Of the 13 teaching hospitals in our sample, 11 are notfor-profits and 2 are government-owned.

An alternative to separating the sample by ownership status is to include right-hand side indicators for three of the four ownership types in the estimation. We chose to separate the sample by ownership status because previous research has indicated that hospital ownership status is related to characteristics of the hospital's location, some of which are not observable to the researcher (Norton and Staiger 1994). If these unobserved location characteristics also affect the mean quality of physicians, then hospital ownership is endogenous and the results will be biased.

\section{RESULTS}

Tables 3 and 4 report results from estimating equations (1) and (2). Table 3 reports results on the relationship between patient payment type and physician quality for all cardiac patients in all hospitals, and in Table 4 patients are divided according to ownership status of the admitting hospital. Both sets of estimates included the same independent variables, however we only 
present the coefficients on ability to pay in Table 4 . Medicare patients are the comparison group.

Relative to Medicare patients, uninsured patients are more likely to be treated by physicians who are from lower quality U.S. medical schools, have fewer years of experience, and who are less likely to be board certified; all results are significant at the one or five percent level of significance. Results in column (1) of Table 3 indicate that uninsured patients are treated by physicians who are from medical schools with Gourman scores below the average physician's medical school score in the hospital. ${ }^{2}$ Since the Gourman scores range from a maximum value of 4.93 to a minimum of 2.06, small changes could indicate noticeable differences in school quality. For example, Cornell University, ranked $9^{\text {th }}$ in the country by the Princeton Review and $8^{\text {th }}$ by the U.S. News and World Report, has a Gourman score of 4.84. In comparison, Brown University has a Gourman score of 4.14, but is ranked much lower: $51^{\text {st }}$ by the Princeton Review and $54^{\text {th }}$ by the U.S. News and World Report.

Medicaid patients are also treated by lower quality physicians by all quality measures, and all results are significant at the one percent level. The effect of Medicaid on physician quality depends on the level of payments received in a particular state. In the state of Florida, for certain groups of patients - such as obstetrics and newborns - the payments from Medicaid are often comparable to private insurance payments. In the cardiac care category that we are studying, however, Medicaid payments are significantly lower than private insurance payments, and often below costs (Florida Hospital Association 2006). This may contribute to the observed sign on Medicaid patients; providers are guaranteed a payment rate lower than that received by Medicare and presumably private insurance companies.

The results in column (3) of Table 3 present the estimated coefficients for the probit model, where the dependent variable is an indicator the physician is board certified. Relative to 
Medicare patients, being uninsured decreased the probability of receiving a board certified physician by 5.6 percentage points. Having Medicaid decreases the probability of receiving a board certified physician by 4.2 percentage points, relative to Medicare patients. ${ }^{3}$

The primary diagnosis-related groups, ICISS, and secondary diagnosis indicators are included to control for patients' health. The excluded primary diagnoses are 'mild' diagnoses such as chest pain, and a higher ICISS score indicates a better chance of survival. Overall the results have the expected signs that patients with more severe diagnoses receive higher quality physicians. Patients who have cancer or who have had a prior myocardial infarction are also more likely to receive a higher quality physician.

Despite controlling for patient demographic characteristics and health and diagnoses, these results indicate that hospitals are sorting patients by insurance type to lower quality physicians. Next we divide the sample by hospital ownership to determine if this sorting process is consistent in different hospital ownership types.

In Table 4 all hospital types treat uninsured patients with lower quality physicians, using at least one measure of physician quality. In not-for-profit hospitals, the most common type of hospital, uninsured patients are treated by less experienced physicians, but the results on school quality and board certification are insignificant. Medicaid patients in not-for-profit hospitals are treated by lower quality physicians by all quality measures, with all results significant at least at the 5 percent level.

In two cases commercially insured patients receive preferential treatment; they are treated by physicians from higher quality schools in teaching hospitals and are more likely to be treated by board certified physicians in government hospitals. Teaching hospitals are also the only hospital type with significantly negative results on all three of the physician quality measures for the 
uninsured. This may in part be related to the fact that teaching hospitals generally have a higher percentage of uninsured patients than not-for-profit and for-profit hospitals, so the incentive for sorting patients is greater.

Medicaid and uninsured patients are both treated by lower quality physicians relative to Medicare patients, after controlling for patient demographic and health characteristics. Since Medicaid patients provide some level of payment to providers whereas the uninsured may not, there is a question of why Medicaid patients are at least as likely to be discriminated against. One answer is that hospitals can be altruistic, and therefore derive utility from the provision of care to the uninsured but this altruism may not extend to Medicaid patients. Frank and Salkever (1991) argue that even for-profit hospitals have an incentive to provide care to the uninsured because the provision of such care may have a positive impact on the hospital's rapport with regulatory agencies. Another explanation may be that the uninsured category includes self-pay patients who may actually be able to make some payments.

\section{DISCUSSION}

Using cardiac patients requiring urgent care, we compared the quality of physicians treating patients of different insurance status within a hospital. Overall there is strong evidence that patients who are uninsured or on Medicaid are significantly more likely to be treated by lower quality physicians. Controlling for patient characteristics and the quality and availability of other physicians within a hospital, uninsured and Medicare patients are more likely to be treated by physician who are not board certified, are from lower quality medical schools, and who have fewer years of experience. After separating our data by hospital ownership type, we further find that all hospital ownership types treat uninsured patients with lower quality physicians by at least 
one measure of physician quality. We also determined that in each hospital type Medicaid patients were discriminated against using at least one of the physician quality measures.

Outcomes already reported in the news include long waiting times and significant crowding in hospital emergency rooms, and increasingly frequent complaints from emergency physicians that the uninsured are not emergency patients when they come through the emergency rooms. Our results suggest that sorting uninsured and Medicaid patients to lower quality physicians is another result of poor access to quality health care.

\section{NOTES}

1. Results from the first step of the Heckman model indicate that Medicaid patients are significantly less likely to be treated by a physician graduate of a U.S. medical school relative to Medicare patients, but neither the uninsured nor the privately-insured patients are less likely to be treated by a domestically trained physician. Patients are more likely to be treated by a domestically-trained physician if they have a more severe diagnosis and/or lower survival risk, and less likely if they are black or Hispanic.

2. Although much research has looked at the determinants of a patient's choice of hospital, there has been very little work on the variance in patients' treatment within a hospital (an exception is Doyle 2005).

3. We obtained the predicted values when the uninsured (Medicaid) indicator equals zero, and when it equals one. The Medicaid (uninsured) and commercial insurance indicators were set to zero and means of all other right-hand side variables used. The predicted value of an uninsured, Medicaid, or Medicare patient receiving a board certified physician is $0.38,0.39$, or 0.44 , respectively. Using the cumulative standard normal distribution function evaluated at each of the predicted values, the marginal effect of being uninsured or on Medicaid is -0.021 or -0.015 , respectively.

\section{REFERENCES}

Agency for Healthcare Research and Quality. 2004. "Variations in outcomes is small for CABG surgery patients treated at high-volume vs. lower volume hospitals.”

http://www.ahrq.gov/research/jun04/0604RA4.htm.

Baker, D.W., J.J. Sudano, J.M. Albert, E. A. Borawski, and A. Dor. 2001. “Lack of Health Insurance and Decline in overall Health in Late Middle Age.” The New England Journal of Medicine 345(15): 1106-1112. 
Canto, J.G., W.J. Rogers, W.J. French, J.M. Gore, N.C. Chandra, and H.V. Barron. 2000. “Payer Status and the Utilization of Hospital Resources in Acute Myocardial Infarction.” Archives of Internal Medicine 160: 817-823.

Chalkley, M., and J.M. Malcolmson. 1998. “Contracting for Health Services When Patient Demand Does Not Reflect Quality.” Journal of Health Economics 17(1): 1-19.

Currie J., and J. Gruber. 1996. "Health Insurance Eligibility, Utilization of Medical Care, and Child Health.” The Quarterly Journal of Economics 1996a: 431-455.

Doyle, J. 2005. "Health Insurance, Treatment and Outcomes: Using Auto Accidents as Health Shocks,” Review of Economics and Statistics 87(2): 256-270.

Ellis, R.P., and T.G. McGuire. 1986. "Provider Behavior under prospective reimbursement: Cost Sharing and Supply.” Journal of Health Economics 5: 129-151.

Florida Hospital Association. 2006. http://www.fha.org.

Frank, R., and D. Salkever. 1991. "The Supply of Charity Services by nonprofit hospitals: motives and market structure.” The RAND Journal of Economics 22(3): 430-445.

Hadley J. 1988. “Medicare Spending and Mortality Rates of the Elderly.” Inquiry 25: 485-493.

Hadley J., E.P. Steinberg, and M. Klag. 1992. “A Comparison of Insured vs. Uninsured Individuals who died from Acute Myocardial Infarction.” Center for Health Policy Studies 1-23.

Huynh, T., J. Guy, and R. Rutledge. 1998. “An ICD-9 Based Illness Severity Score (ICISS) Out Performs Apache II In Predicting Survival, Hospital Charges and Length of Stay in Surgical Intensive Care Unit Patients.” Critical Care Medicine 26(1S) Supplement, 25A.

Jha, A. K., and A. M. Epstein. 2006. "The Predictive Accuracy of The New York State Coronary Artery Bypass Surgery Report-Card System.” Health Affairs 25(3): 844 - 855.

Kozak L.J., M.J. Hall, and M.F. Owings. 2001. “Trends in Avoidable Hospitalizations.” Health Affairs 20(2): 225-232.

Kreindel S., R. Rosetti, and R. Goldberg. 1997. "Health Insurance Coverage and Outcome following Acute Myocardial Infarction: A community -wide Perspective.” Archives of Internal Medicine 157: 758-762.

Lichtenberg F.R. 2001. “The Effects of Medicare on Health Care Utilization and Outcomes.” in Garber, A.M. ed. Frontiers in Health Policy Research, Vol. 5, NBER, pp. 1-38.

Ma, A.C. 1994. “Health Care Payment Systems: Cost and Quality Incentives.” Journal of Economics and Management Strategy 3(1), 93-112. 
Norton, E.C., and D.O. Staiger. 1994. "How Hospital Ownership affects Access to Health Care for the Uninsured.” The RAND Journal of Economics 25(1): 171-185.

Osler, T., R. Rutledge, J. Deis, and E. Bedrick. 1996. "ICISS: An International Classification of Disease-9 Based Injury Severity Score.” Journal of Trauma-Injury Infection \& Critical Care 41(3): 380-388.

Pappas G., W.C. Hadden, L.J. Kozak, and G.F. Fisher. 1997. "Potentially Avoidable Hospitalizations: Inequalities in Rates between US Socioeconomic Groups.” American Journal of Public Health 87(5): 811-816.

Pope, G.C. 1989. "Hospital Nonprice Competition and Medicare Reimbursement Policy.” Journal of Health Economics 8(2), 147-172.

Rutledge, R., O. Turner, S. Emery, and S. Kromhout-Schire. 1998. “The End of the Injury Severity Score (ISS) and the Trauma and Injury Severity Score (TRISS): ICISS, an International Classification of Diseases, Ninth Revision-Based Prediction Tool, Outperforms Both ISS and TRISS as Predictors of Trauma Patient Survival, Hospital Charges, and Hospital Length of Stay.” Journal of Trauma: Injury, Infection and Critical Care 44: 41-49.

Silverman, E., and J. Skinner. 2004. "Medicare Upcoding and Hospital Ownership.” Journal of Health Economics 23(2): 369-389.

Sloan, F.A., G.A. Picone, D.H. Taylor, and S. Chou. 2001. "Hospital Ownership and cost and quality of care: is there a dime's worth of difference?” Journal of Health Economics 20(1): 1-21.

Weissman, J., E. Moy, E. Campbell, and M. Gokhale. 2003. "Limits to the Safety net: Teaching hospital faculty report on their patients’ access to care.” Health Affairs 22(6): 156-166.

Wen, H., C. Tang, H. Lin, C. Tsai, C. Chen, and C. Li. 2006. “Association between surgeon and hospital volume in coronary artery bypass graft surgery outcomes: A population-based study.” The Annals of Thoracic Surgery 81: 834-842.

Young, G., and B. Cohen. 1991. "Inequities in hospital care, the Massachusetts Experience.” Inquiry 28(3): 255-262. 
Table 1. Pairwise Correlations: Physician Quality and Patient Severity Measures

\begin{tabular}{|c|c|c|c|c|}
\hline & $\begin{array}{l}\text { Princeton Review's Scores } \\
\text { of U.S. Medical Schools }\end{array}$ & $\begin{array}{c}\text { Years of } \\
\text { Experience }\end{array}$ & $\begin{array}{l}\text { Board } \\
\text { Certified }\end{array}$ & $\begin{array}{l}\text { ICISS- Survival } \\
\text { Probability }\end{array}$ \\
\hline $\begin{array}{l}\text { Princeton Review’s Scores } \\
\text { of US Medical Schools }\end{array}$ & 1.000 & & & \\
\hline Years of Experience & $\begin{array}{c}0.046 \\
(0.000)\end{array}$ & 1.000 & & \\
\hline Board Certified & $\begin{array}{c}0.077 \\
(0.000)\end{array}$ & $\begin{array}{c}0.173 \\
(0.000)\end{array}$ & 1.000 & \\
\hline ICISS - Survival Probability & $\begin{array}{l}-0.009 \\
(0.000)\end{array}$ & $\begin{array}{l}-0.025 \\
(0.000)\end{array}$ & $\begin{array}{l}0.000 \\
(0.957)\end{array}$ & 1.000 \\
\hline $\begin{array}{l}\text { DRG Code (smaller - more } \\
\text { difficult procedures) }\end{array}$ & $\begin{array}{l}-0.017 \\
(0.000)\end{array}$ & $\begin{array}{l}-0.020 \\
(0.000)\end{array}$ & $\begin{array}{l}-0.009 \\
(0.000)\end{array}$ & $\begin{array}{c}0.388 \\
(0.000)\end{array}$ \\
\hline
\end{tabular}


Table 2. Patient, Physician, and Hospital Characteristics, by Patient Payment Type

\begin{tabular}{|c|c|c|c|c|c|c|c|}
\hline Number of Persons: & Min & Max & $\begin{array}{l}\text { Overall } \\
259,046 \\
\end{array}$ & $\begin{array}{c}\text { Uninsured } \\
15,705 \\
\end{array}$ & 17,666 & $\begin{array}{c}\text { Commercial } \\
\text { Insurance } \\
55,749 \\
\end{array}$ & 163,919 \\
\hline \multicolumn{8}{|l|}{ Physician Characteristics } \\
\hline Median Medical School Score ${ }^{1}$ & 2.94 & 4.73 & 3.8 & 3.8 & 3.8 & 3.8 & 3.8 \\
\hline Median Years of Experience & 0 & 60 & 13 & 12 & 13 & 13 & 14 \\
\hline Board Certified $(\%)^{2}$ & 0 & 1 & 73 & 71 & 71 & 73 & 74 \\
\hline International medical school grad & 0 & 1 & 35 & 34 & 36 & 35 & 35 \\
\hline \multicolumn{8}{|l|}{ Hospital Characteristics } \\
\hline Not for Profit (\%) & 0 & 1 & 42 & 36 & 33 & 44 & 44 \\
\hline Government (\%) & 0 & 1 & 10 & 13 & 10 & 9 & 9 \\
\hline For-profit (\%) & 0 & 1 & 40 & 38 & 41 & 38 & 41 \\
\hline Teaching (\%) & 0 & 1 & 8 & 12 & 16 & 8 & 6 \\
\hline \multicolumn{8}{|l|}{$\begin{array}{l}\text { Patient Characteristics } \\
\text { Age Indicators (\%): }\end{array}$} \\
\hline Age $0-2$ yrs & 0 & 1 & 0 & 0 & 2 & 0 & 0 \\
\hline Age 3-39 yrs & 0 & 1 & 6 & 17 & 18 & 12 & 1 \\
\hline Age $40-49$ yrs & 0 & 1 & 11 & 31 & 24 & 23 & 2 \\
\hline Age $50-59$ yrs & 0 & 1 & 15 & 29 & 28 & 33 & 5 \\
\hline Age 60-69 yrs & 0 & 1 & 18 & 14 & 19 & 22 & 17 \\
\hline Age $70-79$ yrs & 0 & 1 & 24 & 4 & 6 & 6 & 35 \\
\hline Over 79 yrs & 0 & 1 & 27 & 4 & 3 & 4 & 40 \\
\hline Female (\%) & 0 & 1 & 51 & 39 & 57 & 46 & 53 \\
\hline Black (\%) & 0 & 1 & 15 & 25 & 34 & 16 & 11 \\
\hline Hispanic (\%) & 0 & 1 & 14 & 19 & 28 & 13 & 11 \\
\hline ICISS (patient survival risk) & 0 & 1 & 79 & 84 & 81 & 85 & 75 \\
\hline \multicolumn{8}{|l|}{ DRG Indicators (\%): } \\
\hline Very Severe & 0 & 1 & 5 & 5 & 4 & 7 & 5 \\
\hline Severe & 0 & 1 & 5 & 2 & 3 & 3 & 6 \\
\hline Somewhat Severe & 0 & 1 & 42 & 33 & 40 & 32 & 47 \\
\hline Mild & 0 & 1 & 45 & 59 & 52 & 55 & 39 \\
\hline \multicolumn{8}{|l|}{ Secondary Diagnoses (\%): } \\
\hline Diabetes & 0 & 1 & 16 & 16 & 22 & 15 & 16 \\
\hline Cancer & 0 & 1 & 3 & 1 & 2 & 2 & 3 \\
\hline Dementia & 0 & 1 & 2 & 1 & 1 & 0 & 3 \\
\hline Hypertension & 0 & 1 & 34 & 35 & 34 & 38 & 33 \\
\hline Stroke & 0 & 1 & 2 & 1 & 2 & 1 & 2 \\
\hline Vascular Disease & 0 & 1 & 2 & 1 & 2 & 2 & 3 \\
\hline Pulmonary Disease (COPD) & 0 & 1 & 20 & 14 & 22 & 12 & 24 \\
\hline Respiratory Disease & 0 & 1 & 5 & 4 & 5 & 4 & 6 \\
\hline Previous Myocardial Infarction & 0 & 1 & 3 & 3 & 3 & 3 & 3 \\
\hline Obese & 0 & 1 & 17 & 19 & 19 & 20 & 15 \\
\hline Other Heart Disease & 0 & 1 & 30 & 21 & 23 & 21 & 35 \\
\hline
\end{tabular}

1. The score is based on the numeric Gourman score from the 1997 Princeton Review of medical schools.

2. There are only 160,400 patients treated by physicians with data on school ranking: 9,966 uninsured, 10,938 on Medicaid, 104,478 on Medicare, and 35,018 with private insurance.

3. There are 227,180 patients treated by physicians with data on board certification: 13,971 uninsured, 15,772 on Medicaid, 149,048 on Medicare, and 48,389 with private insurance. 
Table 3. The Effects of Patient Payment Type on Quality of Physician

\begin{tabular}{|c|c|c|c|c|c|c|}
\hline \multirow[b]{2}{*}{ Payment Type: } & \multicolumn{2}{|c|}{$\begin{array}{l}\text { Ranking of } \\
\text { Medical School } \\
(\mathrm{n}=160,400)\end{array}$} & \multicolumn{2}{|c|}{$\begin{array}{c}\text { Years of } \\
\text { Experience } \\
(\mathrm{n}=259,046)\end{array}$} & \multicolumn{2}{|c|}{$\begin{array}{c}\text { Board } \\
\text { Certification } \\
(\mathrm{n}=227,180) \\
\end{array}$} \\
\hline & & & & & & \\
\hline Uninsured & $-0.014 * *$ & $(0.007)$ & $-0.652 * * *$ & $(0.082)$ & $-0.056 * * *$ & $(0.013)$ \\
\hline Medicaid & $-0.025 * * *$ & $(0.007)$ & $-0.299 * * *$ & $(0.078)$ & $-0.042 * * *$ & $(0.012)$ \\
\hline Private Insurance & $0.017 * * *$ & $(0.005)$ & $-0.106 * *$ & $(0.055)$ & $0.017 *$ & $(0.009)$ \\
\hline Age $0-2$ years & 0.020 & $(0.592)$ & 0.294 & $(0.493)$ & 0.037 & $(0.072)$ \\
\hline Age 3-39 years & -0.001 & $(0.008)$ & $-0.627 * * *$ & $(0.095)$ & $-0.032 * *$ & $(0.015)$ \\
\hline Age $40-49$ years & -0.005 & $(0.006)$ & $-0.702 * * *$ & $(0.077)$ & -0.005 & $(0.012)$ \\
\hline Age 50-59 years & $-0.011 * *$ & $(0.006)$ & $-0.468 * * *$ & $(0.069)$ & -0.010 & $(0.011)$ \\
\hline Age $60-69$ years & $-0.012 * * *$ & $(0.005)$ & $-0.422 * * *$ & $(0.059)$ & $-0.015^{*}$ & $(0.009)$ \\
\hline Age 70-79 years & -0.006 & $(0.004)$ & $-0.316^{* * *}$ & $(0.051)$ & -0.005 & $(0.008)$ \\
\hline Female & 0.009 & $(0.003)$ & $0.096^{* * *}$ & $(0.036)$ & 0.006 & $(0.006)$ \\
\hline Black & 0.001 & $(0.005)$ & $-0.102 *$ & $(0.056)$ & $-0.014^{*}$ & $(0.009)$ \\
\hline Hispanic & -0.004 & $(0.006)$ & $-0.353 * * *$ & $(0.068)$ & $-0.026 * *$ & $(0.011)$ \\
\hline ICD 9 Injury Severity Score & 0.017 & $(0.011)$ & $-0.487 * * *$ & $(0.141)$ & $0.085^{* * *}$ & $(0.022)$ \\
\hline \multicolumn{7}{|l|}{ Principal Diagnosis: } \\
\hline Very Severe & $0.096 * * *$ & $(0.007)$ & 0.041 & $(0.090)$ & $-0.089 * * *$ & $(0.014)$ \\
\hline Severe & 0.005 & $(0.007)$ & $0.926 * * *$ & $(0.089)$ & $0.058 * * *$ & $(0.013)$ \\
\hline Somewhat Severe & $0.008 * *$ & $(0.003)$ & -0.008 & $(0.041)$ & $0.098 * * *$ & $(0.006)$ \\
\hline \multicolumn{7}{|l|}{ Secondary Diagnosis: } \\
\hline Diabetes & -0.006 & $(0.004)$ & 0.000 & $(0.049)$ & -0.004 & $(0.008)$ \\
\hline Cancer & $0.023^{* * *}$ & $(0.009)$ & $0.312^{* * *}$ & $(0.115)$ & 0.018 & $(0.018)$ \\
\hline Dementia & $-0.021 * *$ & $(0.010)$ & 0.015 & $(0.128)$ & -0.013 & $(0.019)$ \\
\hline Hypertension & 0.001 & $(0.003)$ & $-0.127 * * *$ & $(0.040)$ & 0.005 & $(0.006)$ \\
\hline Stroke & 0.004 & $(0.011)$ & 0.116 & $(0.131)$ & 0.020 & $(0.020)$ \\
\hline Vascular Disease & $-0.026 * * *$ & $(0.010)$ & 0.176 & $(0.120)$ & 0.015 & $(0.019)$ \\
\hline Old Myocardial Infarction & -0.006 & $(0.008)$ & $0.240 * *$ & $(0.106)$ & $0.057 * * *$ & $(0.016)$ \\
\hline Other Heart Disease & 0.002 & $(0.003)$ & 0.005 & $(0.040)$ & 0.000 & $(0.006)$ \\
\hline Obesity & 0.006 & $(0.004)$ & 0.038 & $(0.048)$ & 0.006 & $(0.007)$ \\
\hline Monday & $-0.015^{* * *}$ & $(0.005)$ & 0.010 & $(0.055)$ & -0.005 & $(0.009)$ \\
\hline Tuesday & $-0.015 * * *$ & $(0.005)$ & 0.038 & $(0.056)$ & $-0.015^{*}$ & $(0.009)$ \\
\hline Wednesday & -0.007 & $(0.005)$ & -0.037 & $(0.057)$ & -0.009 & $(0.009)$ \\
\hline Thursday & -0.002 & $(0.005)$ & -0.037 & $(0.057)$ & -0.007 & $(0.009)$ \\
\hline Sunday & -0.005 & $(0.005)$ & 0.096 & $(0.063)$ & -0.006 & $(0.010)$ \\
\hline Foreign Physician & & & $1.777 * * *$ & $(0.038)$ & $-0.088 * * *$ & $(0.006)$ \\
\hline Constant & 0.071 & $(0.022)$ & $1.737 * * *$ & $(0.257)$ & $0.524 * * *$ & $(0.040)$ \\
\hline Mill's ratio & $0.121 * * *$ & $(0.009)$ & & & & \\
\hline R-squared & 0.06 & & 0.04 & & 0.04 & \\
\hline
\end{tabular}


Table 4. The Effects of Patient Payment Type on Quality of Physician, by Hospital Type

\begin{tabular}{|c|c|c|c|c|}
\hline \multirow{2}{*}{\multicolumn{5}{|c|}{$\begin{array}{l}\text { Payment Type } \\
\text { A. Gourman Scores of U.S. Medical Schools }\end{array}$}} \\
\hline & & & & \\
\hline & Government & Not-for-Profit & Teaching & For-profit \\
\hline Uninsured & $\begin{array}{l}0.021 \\
(0.020)\end{array}$ & $\begin{array}{l}-0.003 \\
(0.011)\end{array}$ & $\begin{array}{l}-0.058^{* * *} \\
(0.022)\end{array}$ & $\begin{array}{l}-0.023^{* *} \\
(0.011)\end{array}$ \\
\hline Medicaid & $\begin{array}{l}-0.017 \\
(0.021)\end{array}$ & $\begin{array}{l}-0.025^{* *} \\
(0.011)\end{array}$ & $\begin{array}{l}-0.016 \\
(0.018)\end{array}$ & $\begin{array}{l}-0.024^{* *} \\
(0.010)\end{array}$ \\
\hline Commercial Insurance & $\begin{array}{l}0.003 \\
(0.015)\end{array}$ & $\begin{array}{l}-0.030 * * * \\
(0.007)\end{array}$ & $\begin{array}{l}0.089 * * * \\
(0.017)\end{array}$ & $\begin{array}{l}-0.025^{* * *} \\
(0.007)\end{array}$ \\
\hline Number of Observations & 15,884 & 68,251 & 11,723 & 64,328 \\
\hline R-squared & 0.05 & 0.06 & 0.05 & 0.06 \\
\hline \multicolumn{5}{|c|}{ B. Physician's Years of Experience } \\
\hline & Government & Not-for-Profit & Teaching & For-profit \\
\hline Uninsured & $\begin{array}{l}-1.355^{* * *} \\
(0.228)\end{array}$ & $\begin{array}{l}-0.479 * * * \\
(0.137)\end{array}$ & $\begin{array}{l}-0.879 * * * \\
(0.236)\end{array}$ & $\begin{array}{l}-0.507^{* * *} \\
(0.132)\end{array}$ \\
\hline Medicaid & $\begin{array}{l}-0.573^{* *} \\
(0.260)\end{array}$ & $\begin{array}{l}-0.464^{* * *} \\
(0.134)\end{array}$ & $\begin{array}{l}-0.493^{* *} \\
(0.208)\end{array}$ & $\begin{array}{l}-0.049 \\
(0.120)\end{array}$ \\
\hline Commercial Insurance & $\begin{array}{l}0.056 \\
(0.184)\end{array}$ & $\begin{array}{l}-0.095 \\
(0.084)\end{array}$ & $\begin{array}{l}-0.336^{*} \\
(0.187)\end{array}$ & $\begin{array}{l}-0.145^{*} \\
(0.086)\end{array}$ \\
\hline Number of Observations & 25,698 & 109,488 & 20,720 & 102,821 \\
\hline R-squared & 0.06 & 0.04 & 0.05 & 0.05 \\
\hline \multicolumn{5}{|c|}{ C. Indicator Physician is Board Certified } \\
\hline Uninsured & $\begin{array}{l}\text { Government } \\
-0.073^{* *} \\
(0.035)\end{array}$ & $\begin{array}{l}\text { Not-for-Profit } \\
-0.029 \\
(0.022)\end{array}$ & $\begin{array}{l}\text { Teaching } \\
-0.210^{* * *} \\
(0.038)\end{array}$ & $\begin{array}{l}\text { For-profit } \\
-0.007 \\
(0.022)\end{array}$ \\
\hline Medicaid & $\begin{array}{l}-0.007 \\
(0.037)\end{array}$ & $\begin{array}{l}-0.052 * * \\
(0.022)\end{array}$ & $\begin{array}{l}-0.096 * * * \\
(0.033)\end{array}$ & $\begin{array}{l}-0.041^{* *} \\
(0.020)\end{array}$ \\
\hline Commercial Insurance & $\begin{array}{l}0.094^{* * *} \\
(0.027)\end{array}$ & $\begin{array}{l}-0.013 \\
(0.014)\end{array}$ & $\begin{array}{c}0.019 \\
(0.030)\end{array}$ & $\begin{array}{c}0.024 \\
(0.015)\end{array}$ \\
\hline Number of Observations & 22,557 & 94,457 & 18,792 & 90,839 \\
\hline Pseudo R-squared & 0.04 & 0.05 & 0.03 & 0.05 \\
\hline \multicolumn{5}{|c|}{$\begin{array}{l}\text { Models include hospital fixed effects. Robust standard errors in parentheses. } \\
\text { Omitted Insurance Category is privately-insured patients. } \\
\text { Estimations results for all included variables are available from the authors upon request. }\end{array}$} \\
\hline
\end{tabular}

